\title{
Cryptic species of Paracoccidioides brasiliensis: impact on paracoccidioidomycosis immunodiagnosis
}

\author{
Gabriel Capella Machado', Daniela Vanessa Moris², Thales Domingos Arantes, \\ Luciane Regina Franciscone Silva ${ }^{3}$, Raquel Cordeiro Theodoro', \\ Rinaldo Pôncio Mendes², Adriana Pardini Vicentini ${ }^{3}$ Eduardo Bagagli++ \\ ${ }^{1}$ Departamento de Microbiologia e Imunologia, Instituto de Biociências de Botucatu ${ }^{2}$ Departamento de Doenças Tropicais, \\ Faculdade de Medicina de Botucatu, Universidade Estadual Paulista Júlio de Mesquita Filho, Botucatu, SP, Brasil \\ ${ }^{3}$ Laboratório de Imunodiagnóstico das Micoses, Centro de Imunologia, Instituto Adolfo Lutz, São Paulo, SP, Brasil
}

\begin{abstract}
We aimed to evaluate whether the occurrence of cryptic species of Paracoccidioides brasiliensis, S1, PS2, PS3 and Paracoccidioides lutzii, has implications in the immunodiagnosis of paracoccidioidomycosis (PCM). Small quantities of the antigen gp 43 were found in culture filtrates of $\mathrm{P}$. lutzii strains and this molecule appeared to be more variable within P. lutzii because the synonymous-nonsynonymous mutation rate was lower, indicating an evolutionary process different from that of the remaining genotypes. The production of gp43 also varied between isolates belonging to the same species, indicating that speciation events are important, but not sufficient to fully explain the diversity in the production of this antigen. The culture filtrate antigen AgEpm83, which was obtained from a PS3 isolate, showed large quantities of gp 43 and reactivity by immunodiffusion assays, similar to the standard antigen (AgB-339) from an S1 isolate. Furthermore, AgEpm83 was capable of serologically differentiating five serum samples from patients from the Botucatu and Jundiai regions. These patients had confirmed PCM but, were non-reactive to the standard antigen, thus demonstrating an alternative for serological diagnosis in regions in which S1 and PS2 occur. We also emphasise that it is not advisable to use a single antigen preparation to diagnose PCM, a disease that is caused by highly diverse pathogens.
\end{abstract}

Key words: Paracoccidioides spp - cryptic species - antigen preparations - immunodiagnosis - gp43

The thermal dimorphic fungus Paracoccidioides brasiliensis belongs to the phylum Ascomycota and is the etiological agent of paracoccidioidomycosis (PCM) (Lacaz 1994), the most important systemic mycosis in Latin America. This disease mainly affects male rural workers and is endemic from Mexico to Argentina (Franco et al. 1993). In its mycelial form, P. brasiliensis lives saprophytically on the ground, producing such propagules as arthroconidia and aleuroconidia that can infect humans (Franco et al. 1994), dogs (Ricci et al. 2004, Farias et al. 2005), armadillos (Naiff et al. 1986, Bagagli et al. 1998, 2003, Corredor et al. 1999) and sloths (Trejo-Cháves et al. 2011). The inhalation of infective fungal propagules present in the environment is believed to be the route of infection in both human and non-human vertebrate hosts (McEwen et al. 1987). Once inhaled and ensconced in the pulmonary alveoli, the infective forms (mycelia and/or conidia) are converted into the parasitic form, i.e., yeast cells.

Multilocus genealogy findings have shown that $P$. brasiliensis is in fact a complex of four reproductively iso-

doi: 10.1590/0074-0276108052013016

Financial support: CNPq (137704/2009-7)

+ Corresponding author: bagagli@ibb.unesp.br

Received 20 December 2012

Accepted 17 May 2013 lated cryptic species. Three species, including one paraphyletic (S1) and two monophyletic (PS2 and PS3) species, were first described by Matute et al. (2006). S1 and PS2 occur in the same geographic areas (Brazil, Argentina, Peru, Paraguay and Venezuela), whereas PS3 is restricted to Colombia. The phylogenetic analysis of 14 genes in 21 isolates revealed that isolate $\mathrm{Pb} 01$ could not be grouped into any of these species and constituted a new clade (Carrero et al. 2008). Additionally, 17 new isolates belonging to this fourth cryptic species (Pb01-like) were identified, 16 of which are from the Central-West Region of Brazil, whereas the other isolates is from Ecuador (Teixeira et al. 2009). As the Pb01-like isolates are separated from the remaining three species composing $P$. brasiliensis by very divergent phylogenetic branches, $\mathrm{Pb} 01$ will soon be formally described as Paracoccidioides lutzii (MM Teixeira et al., unpublished observations) after the mycologist Dr Adolpho Lutz, who described the morphology of $P$. brasiliensis. Cryptic species in $P$. brasiliensis still require further elucidation with regard to aspects related to their ecoepidemiology, diagnosis, clinical manifestation and response to antifungal treatments.

The definitive diagnosis of PCM requires a direct demonstration of the fungus by fresh sputum, lesion scraping or lymph node aspirate examination and by the assessment of biopsied material from supposedly affected organs (Shikanai-Yasuda et al. 2006). However, the patient's clinical condition frequently impairs the collection of the biological material needed for this procedure (Ferreira-da-Cruz et al. 1990). 
The double agar-gel immunodiffusion (DID) test has been performed for the past half century for the routine serological diagnosis of PCM (Ferri 1961, Shikanai-Yasuda et al. 2006). In many cases, DID presents excellent sensitivity, specificity, predictive values (positive and negative) and accuracy (Moreto et al. 2011). In addition, the technique is practical and imposes a low operational cost. Indeed, a direct correlation between the serum levels of antibodies detected by DID and disease severity has been demonstrated (Biagioni et al. 1984, Moreto et al. 2011) and is one of the parameters considered in the classification of the clinical form and severity of the disease (Mendes 1994). During efficacious treatment, the serum antibody levels detected by DID decrease progressively (Mendes-Giannini et al. 1990, Blotta \& Camargo 1993, Elias-Costa et al. 2000) until becoming negative, thereby constituting the most useful test for PCM control of cure (Mendes et al. 1994). Although DID evaluates humoral immunity, a direct correlation has been observed between a decrease in serum antibody levels, a decrease in interleukin (IL)-10 and an increase in IL-2 and interferon-gamma production by peripheral mononuclear cells in PCM patients (Benard et al. 2001).

These findings show the importance of serological tests in treating PCM patients. Therefore, the choice of the antigen used in DID is a pivotal aspect of this test. However, a consensus on the isolate that should be employed to produce the antigen used in this technique has not yet been reached (Vicentini 2008).

The glycoprotein gp43 (molecular weight of $43 \mathrm{kDa}$ ) is considered to be the immunodominant antigen in $P$. brasiliensis. Patients affected by severe PCM forms show high levels of anti-gp43 antibodies, which decrease over the course of disease treatment in most cases (MendesGiannini et al. 1990, Blotta \& Camargo 1993). Studies have indicated that gp43 acts as a laminin receptor, thus favouring the adhesion, colonisation and propagation of the pathogen (Vicentini et al. 1994, Gesztesi et al. 1996, Mendes-Giannini et al. 2006).

The levels of gp43 may vary according to the isolate and analyses of antigens obtained from the B-339 and 550B isolates showed that the former produced high levels of gp 43, which was undetected in the 550B filtrate (Batista Jr et al. 2010). It must be emphasised that B-339 belongs to the $\mathrm{S} 1$ species, whereas $550 \mathrm{~B}$ is from the Central-West Region of Brazil where P. lutzii predominates. Such variation in gp43 expression most likely influences the low reactivity observed in DID tests using sera from patients from the Central-West Region of Brazil. In addition, different serum samples from a patient from the state of Paraná, who had lived in Botucatu County, but was infected with a $P$. lutzii isolate, tested negative for the antigen that is considered to be the standard and is produced by the B-339 isolate (Takayama et al. 2010). Recombinant gp43 isoforms expressed in other yeasts, such as Pichia pastoris, have emerged as a promising alternative for use in PCM serological diagnosis and will certainly be employed in the near future (Carvalho et al. 2008).

Using the DID test, the present study aimed to evaluate the performance of antigens from different isolates of the P. brasiliensis complex against sera from variable Brazil- ian regions and to elucidate the gp 43 antigenic diversity and variability within the species complex because these aspects may influence immunological diagnoses.

\section{SUBJECTS, MATERIALS AND METHODS}

P. brasiliensis isolates and patient sera - Five human P. brasiliensis isolates were included in this study, one belonging to the S1 species from Botucatu, state of São Paulo (SP), Brazil (Pb265), one of the PS3 species from Colombia (Epm83) and the other three belonging to $P$. lutzii from Goiânia, state of Goiás, Brazil (Pb01, Pb8334 and $\mathrm{Pb} 66$ ). The isolates were maintained on BBL ${ }^{\mathrm{TM}} \mathrm{My}-$ cosel $^{\mathrm{TM}}$ Agar (BD Biosciences, Sparks, MD, USA) and transformed into the yeast phase on $4 \%$ glucose, $1 \%$ peptone, $0.5 \%$ yeast extract and $1 \%$ agar medium. Furthermore, the antigen obtained via filtration of a B-339 culture, considered the standard antigen for immunodiffusion assays, was added to the analyses; this isolate was maintained on potato agar medium and transformed into yeast on Fava-Netto agar.

Regarding the sera from PCM patients, 71 samples were evaluated and divided regionally, as follows: 20 serum samples from Botucatu, 20 from Jundiaí and 31 from the Central-West Region of Brazil. The sera from the Botucatu region were stored in the serum bank at the Laboratory of Tropical Diseases-Mycology Area of Botucatu Medical School of São Paulo State University, whereas the samples from the Jundiai and Central-West regions were stored in the Adolfo Lutz Institute/SP collection.

Preparation of culture-filtered antigen - The yeast cells from each fungal isolate were transferred to 10 slant cultures containing Fava-Netto agar. After five days of growth at $36^{\circ} \mathrm{C}$, the contents of the tubes were inoculated into $500 \mathrm{~mL} 2 \%$ dextrose, $1 \%$ neopeptone, $0.018 \%$ thiamine and $0.036 \%$ asparagine medium and incubated at $35^{\circ} \mathrm{C}$ for 15 days with agitation at $100 \mathrm{rpm}$. After this period, the cells were inactivated with thimerosal $(0.2 \mathrm{~g} / \mathrm{L}$ final concentration) for four days under the same conditions and then filtered through filter paper. The preparations were concentrated using polyethylene glycol until $10 \%$ of the initial volume was reached. The preparations were then dialysed against phosphate buffered saline (PBS) at $\mathrm{pH} 7.2$ for three days at $4^{\circ} \mathrm{C}$. After this period, $1.0-\mathrm{mL}$ aliquots of the samples were separated, lyophilised and, at the moment of use, resuspended in $20 \mu \mathrm{L}$ of PBS.

Other methodologies were also tested to produce such antigens as the somatic antigen (Franco et al. 1996) and the "cell-free" antigen (Camargo et al. 1991), which, in our experience, proved to be less sensitive than the culture-filtered antigen in immunodiffusion assays (data not shown).

DID assays - Carefully cleaned slides were precoated with $1.0 \mathrm{~mL} 1 \%$ agar solution, allowed to dry at $60^{\circ} \mathrm{C}$ for $24 \mathrm{~h}$ and then coated with $3.0 \mathrm{~mL}$ citrate agar solution ( $1 \%$ purified agar, $0.9 \%$ sodium chloride, $0.4 \%$ sodium citrate, $7.5 \%$ glycine or amino acetic acid and $0.01 \%$ thimerosal). The citrate agar was solidified at room temperature (RT) and the slides were stored in a humidified chamber. 
The medium on the slides was bored with the aid of a rosette-shaped mould containing one central and six peripheral holes, each equidistant from the central hole. The slides received $10 \mu \mathrm{L}$ antigen (central well), $10 \mu \mathrm{L}$ polyclonal anti-P. brasiliensis antibody, the positive reaction control and $10 \mu \mathrm{L}$ test serum (peripheral wells), and were incubated in a humidified chamber for $48 \mathrm{~h}$ at RT. After this period, the slides were incubated in $0.5 \%$ sodium citrate solution for $45 \mathrm{~min}$ and in saline solution for $18 \mathrm{~h}$. The wells were then covered with $1 \%$ citrate agar and the slides were wrapped in humid filter paper and allowed to dry for $8 \mathrm{~h}$ at $60^{\circ} \mathrm{C}$. Staining was performed for 10 min with $0.4 \%$ Schwartz starch solution and $10 \%$ glacial acetic acid or Coomassie Blue. Destaining was performed in 5\% glacial acetic acid solution, twice for $10 \mathrm{~min}$ each.

The assessment of the DID results was then performed. The presence of a precipitation line corresponded to an antigen-antibody pair and indicated a positive reaction. The most dubious results were subjected to one or, if necessary, two replicates. In addition, all evaluations were conducted by two different people.

Sodium dodecyl sulphate-polyacrylamide gel electrophoresis (SDS-PAGE) - The gels and reagents for SDSPAGE were prepared as previously described (Laemmli 1970 ); a $10 \%$ resolving gel and $3 \%$ acrylamide stacking gel were used. After electrophoresis, the gels were stained with Coomassie Blue solution $(0.1 \%$ Coomassie Blue, $45 \%$ methanol and $10 \%$ glacial acetic acid) and the excess stain was removed with destaining solution $(10 \%$ glacial acetic acid and $10 \%$ methanol).

Analysis of PbGP43 exon 2 selection pattern - The sequences of PbGP43 exon 2 available in GenBank were employed: 10 haplotypes of $P$. lutzii (accessions: EU870212EU870214, EU870217, EU870218, EU870220, EU870221 and EU870226-EU870228) (Teixeira et al. 2009) and 11 from the other cryptic species (accessions: DQ003724, DQ003741, DQ003744, DQ003746, DQ003748-DQ003750, DQ003771-DQ003773 and DQ003781) (Matute et al. 2006) were used. The sequences were aligned using the software Mega4 and the synonymous and nonsynonymous substitution rates $(\mathrm{dS} / \mathrm{dN})$ were calculated pairwise on the Syn-Scan website (Gonzales et al. 2002) according to the method of Nei-Gojobori (Nei \& Gojobori 1986), yielding a mean $\mathrm{dS} / \mathrm{dN}$ value.

\section{RESULTS}

Double agar gel immunodiffusion test - The results of DID assays performed using 71 serum samples from the Botucatu, Jundiaí and Central-West regions are shown in Table I. Only 10 sera from the Botucatu region reacted against the standard antigen AgB-339 at different titrations. The remaining 10 sera corresponded to patients with active disease or confirmed PCM, but with no reactivity according to DID. Of the five antigen preparations evaluated, the one obtained from the PS3 isolate, Epm83 (AgEpm83), showed the highest reactivity index for the samples from the Botucatu region. In addition to reacting with three sera that were non-reactive to the standard antigen, this antigen was capable of detecting the presence of antibodies in all samples reactive to B-339. AgEpm83 and AgB-339 presented a substantial strength of agreement in the Botucatu region, as represented by a kappa coefficient (k) of 0.7 (Table II). In contrast, $\mathrm{AgPb} 265$ (S1) and $\mathrm{AgPb} 01$ (P. lutzii) did not react with any of the 20 serum samples from the Botucatu patients. The other two antigens produced from the $P$. lutzii isolates $\mathrm{AgPb} 8334$ and $\mathrm{AgPb} 66$ showed identical results $(\mathrm{k}$ $=1.0$ ), reacting with the same eight sera among the 10 positive for AgB-339 and with none of the 10 sera nonreactive to AgB-339. The strength of agreement between these antigens $(\mathrm{AgPb} 8334$ and $\mathrm{AgPb} 66)$ and $\mathrm{AgB}-339$ was also substantial $(\mathrm{k}=0.8)$.

\section{TABLE I}

Reactivity profile shown by culture-filtered antigens in immunodiffusion assays against sera from patients from Botucatu, Jundiaí and Central-West regions of Brazil, reactive or not to the standard antigen AgB-339

\begin{tabular}{|c|c|c|c|c|c|c|}
\hline & & \multicolumn{5}{|c|}{$\begin{array}{c}\text { Reactivity } \\
\text { n (\%) }\end{array}$} \\
\hline & & AgEpm83 & $\mathrm{AgPb} 265$ & $\mathrm{AgPb} 01$ & $\mathrm{AgPb} 8334$ & $\mathrm{AgPb} 66$ \\
\hline \multirow[t]{2}{*}{ Botucatu } & $\begin{array}{l}\text { Reactive sera AgB-339 } \\
\qquad(\mathrm{n}=10)\end{array}$ & $10(100)$ & $0(0)$ & $0(0)$ & $8(80)$ & $8(80)$ \\
\hline & $\begin{array}{l}\text { Non-reactive sera AgB-339 } \\
\qquad(\mathrm{n}=10)\end{array}$ & $3(30)$ & $0(0)$ & $0(0)$ & $0(0)$ & $0(0)$ \\
\hline \multirow[t]{2}{*}{ Jundiaí } & $\begin{array}{l}\text { Reactive sera AgB-339 } \\
\qquad(\mathrm{n}=10)\end{array}$ & $7(70)$ & $2(20)$ & $2(20)$ & $2(20)$ & $3(30)$ \\
\hline & $\begin{array}{l}\text { Non-reactive sera AgB-339 } \\
\qquad(\mathrm{n}=10)\end{array}$ & $2(20)$ & $0(0)$ & $3(30)$ & $3(30)$ & $3(30)$ \\
\hline \multirow[t]{2}{*}{ Central-West Region } & $\begin{array}{l}\text { Reactive sera AgB-339 } \\
\qquad(\mathrm{n}=11)\end{array}$ & $4(36)$ & $1(9)$ & $0(0)$ & $3(27)$ & $4(36)$ \\
\hline & $\begin{array}{l}\text { Non-reactive sera AgB-339 } \\
\qquad(\mathrm{n}=20)\end{array}$ & $0(0)$ & $0(0)$ & $0(0)$ & $0(0)$ & $0(0)$ \\
\hline
\end{tabular}


Regarding the samples from the Jundiai region (10 sera reactive and 10 sera non-reactive to AgB-339), again, AgEpm83 presented the highest reactivity rate among the five antigen preparations. This antigen reacted with seven of the 10 samples reactive to B-339 and with two of the 10 non-reactive samples. However, the $\mathrm{k}$ of these antigens was 0.5 (moderate), demonstrating a weaker agreement in comparison to their performance in the Botucatu region. AgPb265 displayed an unsatisfactory performance, reacting with only two serum samples $(20 \%)$ that were reactive to the standard antigen. A similar reactivity pattern was noted for the three antigens obtained from the $P$. lutzii isolates in sera reactive to the standard antigen: AgPb01 (20\%), $\mathrm{AgPb} 8334$ (20\%) and AgPb66 (30\%). These antigens also showed reactivity to three of the 10 samples negative for the standard antigen. The $\mathrm{k}$ of $\mathrm{AgPb} 01$ and $\mathrm{AgPb} 8334$ was 1.0 (perfect).
The assessment of AgEpm83 performance against the 40 serum samples from the Botucatu and Jundiaí regions, considered to be endemic for $P$. brasiliensis, indicated that this antigen preparation was capable of discriminating among 22 samples, whereas AgB-339 reacted with 20. In addition, AgEpm83 reacted with five of the $20(25 \%)$ sera that were non-reactive to the standard antigen. Interestingly, the $P$. lutzii antigens reacted with five of the serum samples from the Jundiaí region, three of which had not shown reactivity against the antigen AgB-339.

Considering the 31 serum samples from the CentralWest Region of Brazil, 11 showed serological reactivity against the B-339 antigen and none of the evaluated antigen preparations was capable of reacting with more than four of these 11 serum samples. Similarly, none of the 20 sera non-reactive to the standard antigen was reactive to any of these antigens. All of the antigens showed low $\mathrm{k}$ values when compared to the standard antigen.

\section{TABLE II}

Distribution of patients with active paracoccidioidomycosis from different regions as to the hierarchical weights of agreement in serological measures

\begin{tabular}{|c|c|c|c|c|c|c|c|c|c|}
\hline \multirow{2}{*}{$\begin{array}{l}\text { Origen of the patients } \\
\text { Botucatu }\end{array}$} & \multirow{2}{*}{$\begin{array}{l}\text { Comparisons } \\
\text { B339vsEpm83 }\end{array}$} & \multicolumn{2}{|c|}{$\begin{array}{l}\text { Agreements } \\
(++)(--)\end{array}$} & \multicolumn{2}{|c|}{$\begin{array}{c}\text { Disagreements } \\
\quad(+-)(-+)\end{array}$} & \multirow{2}{*}{$\begin{array}{c}\begin{array}{c}\text { Kappa } \\
\text { coefficient }\end{array} \\
0.70\end{array}$} & \multirow{2}{*}{$\begin{array}{c}\begin{array}{c}\text { Confidence } \\
\text { interval }\end{array} \\
0.40-1.00\end{array}$} & \multirow{2}{*}{$\begin{array}{l}\text { Strength of } \\
\text { agreement }\end{array}$} & \multirow{2}{*}{$\begin{array}{c}\text { Mc Nemar's } \\
\text { test } \\
0.08\end{array}$} \\
\hline & & 10 & 7 & 0 & 3 & & & & \\
\hline & $\mathrm{B} 339 \mathrm{vsPb} 265$ & 0 & 10 & 10 & 0 & 0.00 & $0.00-0.44$ & Slight & $<0.01$ \\
\hline & B339vsPb01 & 0 & 10 & 10 & 0 & 0.00 & $0.00-0.44$ & Slight & $<0.01$ \\
\hline & B339vsPb8334 & 8 & 10 & 2 & 0 & 0.80 & $0.54-1.00$ & Substantial & 0.16 \\
\hline & B339vsPb66 & 8 & 10 & 2 & 0 & 0.80 & $0.54-1.00$ & Substantial & 0.16 \\
\hline & $\mathrm{Pb} 01 v s \mathrm{~Pb} 66$ & 0 & 12 & 8 & 0 & 0.00 & $0.00-0.54$ & Slight & $<0.01$ \\
\hline & $\mathrm{Pb} 01 v s \mathrm{~Pb} 8334$ & 0 & 12 & 8 & 0 & 0.00 & $0.00-0.54$ & Slight & $<0.01$ \\
\hline & $\mathrm{Pb} 66 v s \mathrm{~Pb} 8334$ & 8 & 12 & 0 & 0 & 1.00 & $1.00-1.00$ & Perfect & 0.32 \\
\hline & $\mathrm{Pb} 01 v s E p m 83$ & 0 & 7 & 0 & 13 & 0.00 & $0.00-0.32$ & Slight & $<0.01$ \\
\hline & Pb66vsEpm83 & 8 & 7 & 0 & 5 & 0.53 & $0.17-0.89$ & Moderate & 0.0254 \\
\hline & $\mathrm{Pb} 8334 \mathrm{vsEpm} 83$ & 8 & 7 & 0 & 5 & 0.53 & $0.17-0.89$ & Moderate & 0.0254 \\
\hline \multirow[t]{11}{*}{ Jundiaí } & B339vsEpm83 & 7 & 8 & 3 & 2 & 0.50 & $0.12-0.88$ & Moderate & 0.65 \\
\hline & $\mathrm{B} 339 \mathrm{vsPb} 265$ & 2 & 10 & 8 & 0 & 0.20 & $0.00-0.46$ & Slight & $<0.01$ \\
\hline & B339vsPb01 & 2 & 7 & 8 & 3 & 0.00 & $0.00-0.28$ & Slight & 0.13 \\
\hline & B339vsPb8334 & 2 & 7 & 8 & 3 & 0.00 & $0.00-0.28$ & Slight & 0.13 \\
\hline & B339vsPb66 & 3 & 7 & 7 & 3 & 0.00 & $0.00-0.40$ & Slight & 0.21 \\
\hline & $\mathrm{Pb} 01 v s \mathrm{~Pb} 66$ & 4 & 13 & 1 & 2 & 0.62 & $0.23-1.00$ & Substantial & 0.5637 \\
\hline & $\mathrm{Pb} 01 \mathrm{vsPb} 8334$ & 5 & 15 & 0 & 0 & 1.00 & $1.00-1.00$ & Perfect & 0.32 \\
\hline & $\mathrm{Pb} 66 \mathrm{vsPb} 8334$ & 4 & 13 & 2 & 1 & 0.62 & $0.23-1.00$ & Substantial & 0.5637 \\
\hline & Pb01vsEpm83 & 4 & 10 & 1 & 5 & 0.37 & $0.00-0.79$ & Fair & 0.1025 \\
\hline & Pb66vsEpm83 & 4 & 9 & 2 & 5 & 0.27 & $0.00-0.71$ & Fair & 0.2568 \\
\hline & Pb8334vsEpm83 & 4 & 10 & 1 & 5 & 0.37 & $0.00-0.79$ & Fair & 0.1025 \\
\hline \multirow[t]{11}{*}{ Central-West Region } & B339vsEpm83 & 4 & 20 & 7 & 0 & 0.42 & $0.12-0.73$ & Moderate & $<0.01$ \\
\hline & $\mathrm{B} 339 \mathrm{vsPb} 265$ & 1 & 20 & 10 & 0 & 0.11 & $0.00-0.32$ & Slight & $<0.01$ \\
\hline & B339vsPb01 & 0 & 20 & 11 & 0 & 0.00 & $0.00-0.26$ & Slight & 0.01 \\
\hline & $\mathrm{B} 339 \mathrm{vsPb} 8334$ & 3 & 20 & 8 & 0 & 0.33 & $0.03-0.62$ & Fair & $<0.01$ \\
\hline & B339vsPb66 & 4 & 20 & 7 & 0 & 0.42 & $0.12-0.73$ & Moderate & $<0.01$ \\
\hline & $\mathrm{Pb} 01 v s \mathrm{~Pb} 66$ & 0 & 27 & 0 & 4 & 0.00 & $0.00-0.91$ & Slight & 0.0455 \\
\hline & $\mathrm{Pb} 01 v s \mathrm{~Pb} 8334$ & 0 & 28 & 0 & 3 & 0.00 & $0.00-1.00$ & Slight & 0.0833 \\
\hline & $\mathrm{Pb} 66 \mathrm{vsPb} 8334$ & 3 & 27 & 1 & 0 & 0.84 & $0.53-1.00$ & High & 0.3173 \\
\hline & Pb01vsEpm83 & 0 & 27 & 0 & 4 & 0.00 & $0.00-0.90$ & Slight & 0.0455 \\
\hline & Pb66vsEpm83 & 4 & 27 & 0 & 0 & 1.00 & $1.00-1.00$ & Perfect & 0.32 \\
\hline & Pb8334vsEpm83 & 3 & 27 & 0 & 1 & 0.84 & $0.53-1.00$ & High & 0.3173 \\
\hline
\end{tabular}


All the antigen preparations were also evaluated for specificity by a DID assay against nine serum samples from patients with confirmed histoplasmosis and no cross-reaction was noted against the heterologous sera.

$S D S-P A G E$ - Among the antigen preparations, AgEpm 83 had the most evident gp 43 level by SDS-PAGE (Figure) and also exhibited an intense band near $90 \mathrm{kDa}$. The antigens obtained from the $P$. lutzii isolates showed several common bands between 100-60 kDa. AgPb01 and $\mathrm{AgPb} 8334$ showed additional bands at $43 \mathrm{kDa}$, but of lower intensity than the signal for AgEpm83.

Analysis of $d S / d N$ rate of $P b G P 43$ exon 2 - Exon 2 of the $\mathrm{PbGP43}$ gene from the $P$. lutzii and P. brasiliensis groups had a dS/dN mean rate higher than 1.0 (Supplementary data), indicating that the isolates in this region have undergone purifying selection and amino acid sequence conservation (Nei \& Kumar 2000). However, the mean $\mathrm{dS} / \mathrm{dN}$ ratio for the $P$. lutzii group (1.13) was lower than for the P. brasiliensis group (1.52), suggesting that the gp43 amino acid sequence is more variable among the $P$. lutzii isolates.

\section{DISCUSSION}

Comparing the five antigen preparations, the antigen obtained from the Epm 83 isolate had a reactivity profile similar to the profile observed for the standard antigen (AgB-339) against the serum samples from Botucatu. An analysis of the antigenic profile of culture filtrates by SDS-PAGE indicated that AgEpm83 had a more evident band at $43 \mathrm{kDa}$ compared to the other antigens. This finding confirms the importance of the 43-kDa glycoprotein in PCM immunodiagnosis (Puccia et al. 1986), at least for regions in which the S1 and PS2 species occur (Batista Jr et al. 2010). It must be highlighted that the

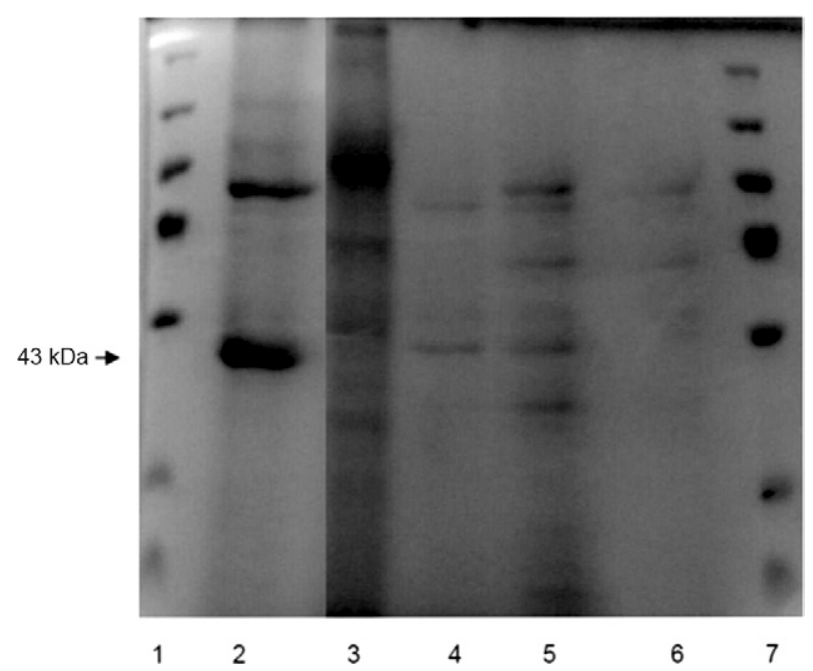

Sodium dodecyl sulphate-polyacrylamide gel electrophoresis in $10 \%$ acrylamide with antigens filtered from culture of Paracoccidioides brasiliensis stained with Coomassie Blue. Lines 1, 7: PageRuler ${ }^{\mathrm{TM}}$ Plus Prestained Protein Ladder (Fermentas); 2: Epm83; 3: Pb265; 4: Pb01; 5: Pb8334; 6: Pb66.
Epm83 isolate belongs to the species PS3 and not to the species occurring in the Botucatu and Jundiaí regions. Regardless, PS3 isolates are known to be phylogenetically close to S1 (Matute et al. 2006, Theodoro et al. 2008, Salgado-Salazar et al. 2010), the most prevalent species in these regions.

The reaction of AgEpm83, associated with high gp43 secretion, with sera non-reactive to the standard antigen in the Botucatu and Jundiaí regions suggests that this specific antigen may serve as an alternative when the standard antigen (AgB-339) is not capable of detecting circulating anti- $P$. brasiliensis antibodies in the residents of regions in which the particular species $\mathrm{S} 1$ and PS2 occur. However, certain samples reactive to AgB339 from the Jundiaí region did not show reactivity against $\mathrm{AgEpm} 83$, resulting in a moderate strength of agreement between these antigens in this region. This finding, associated with the low positivity of AgEpm83 reactivity with serum samples from the Central-West Region of Brazil, indicates that it is not possible to use only a single antigen preparation to diagnose a disease caused by highly diverse agents, particularly in such a large country as Brazil. Additionally, other authors have noted that an antigen produced from an isolate from the Central-West Region of Brazil was capable of reacting with a larger number of sera from that region in comparison to the standard antigen from an isolate from SP (B-339). Nevertheless, when tested with sera from SP, the antigen from Central-West of Brazil did not produce satisfactory results (Batista Jr et al. 2010). These findings confirm the necessity of using different strains to produce antigens and indicate the Epm 83 isolate as a potential alternative that should be further studied.

The present study confirmed the practical difficulties in producing antigens reactive to sera from patients from the Central-West Region of Brazil, even against three isolates of $P$. lutzii, a genotype that appears to be the most prevalent in this region. This difficulty must be related to the greater diversity of gp43 in this species. Given its higher nonsynonymous mutation rate compared to the isolates of the $P$. brasiliensis group, the amino acid sequence of this glycoprotein must be more variable in $P$. lutzii isolates. Thus, patients from Central-West of Brazil would be sensitised by various gp 43 forms, which could explain the difficulty in producing a single antigen reactive in all patients from this region. These facts cast doubt on the potential of gp43 as a universal antigen for all species in immunodiffusion assays, thus requiring a search for new alternatives. In addition to constituting a problem in serological diagnosis, the variability of this antigenic portion could represent an escape mechanism for avoiding host immune responses (Matute et al. 2008).

In addition to presenting several isoforms (Puccia et al. 1986, Moura-Campos et al. 1995), P. brasiliensis strains were observed to express variable quantities of gp 43 (Berzaghi et al. 2005). This result corroborates the difficulty in using this molecule for the universal serological diagnosis of PCM because a patient infected with an isolate that produces gp43 at low rates will not show antibodies specific for this antigen at detectable concentrations. Indeed, the 
determination of variations in the expression of genes encoding gp43 in P. brasiliensis is long-standing, but still unresolved problem. Although a large number of isolates from this group remain to be evaluated, our results suggest that isolates of the P. lutzii group generally have low gp43 production. Speciation events, however, are not sufficient to fully explain the variation in gp 43 rates because not all the isolates of the S1, PS2 and PS3 species produce high quantities of this molecule. Eventual variations in the promoter region of the gp 43 gene among the isolates and interference in posttranscriptional processes, such as alternative splicing and silencing by RNA interference, can influence this variability.

In summary, considering speciation within P. brasiliensis is important for the serological diagnosis of the disease, particularly for the more distant genotypes represented by the $P$. lutzii group. Regarding the group represented by the S1 and PS3 genotypes, the most relevant factor in serological diagnosis is the expression of gp43, which is highly variable among isolates.

\section{ACKNOWLEDGEMENTS}

To Prof Dr Maria José Soares Mendes Giannini, for supplying the protocols for the culture-filtrate antigen extraction.

\section{REFERENCES}

Bagagli E, Franco M, Bosco SMG, Hebeler-Barbosa F, Trinca LA, Montenegro MR 2003. High frequency of Paracoccidioides brasiliensis infection in armadillo (Dasypus novemcinctus): an ecological study. Med Mycol 41: 217-223.

Bagagli E, Sano A, Coelho KIR, Alquati S, Miyaji M, Camargo ZP, Gomes G, Franco M, Montenegro MR 1998. Isolation of Paracoccidioides brasiliensis from armadillos (Dasypus novemcinctus) captured in an endemic area of paracoccidioidomycosis. $\mathrm{Am}$ J Trop Med Hyg 58: 505-512.

Batista Jr J, Camargo ZP, Fernandes GF, Vicentini AP, Fontes CJF, Hanh RC 2010. Is the geographical origin of a Paracoccidioides brasiliensis isolate important for antigen production for regional diagnosis of paracoccidioidomycosis? Mycoses 53: 176-180.

Benard G, Romano CC, Cacere CR, Juvenale M, Mendes-Giannini MJ, Duarte AJ 2001. Imbalance of IL-2, IFN-Y and IL-10 secretion in the immunosuppression associated with human paracoccidioidomycosis. Cytokine 13: 248-252.

Berzaghi R, Silva SH, Camargo ZP 2005. Variable gp43 secretion by Paracoccidioides brasiliensis clones obtained by two different culture methods. J Clin Microbiol 43: 491-493.

Biagioni L, Souza MJ, Chamma LG, Mendes RP, Marques SA, Mota NGS, Franco M 1984. Serology of paracoccidioidomycosis. Correlation between class-specific antibodies and clinical forms of the disease. Trans R Soc Trop Med Hyg 78: 617-621.

Blotta MHSL, Camargo ZP 1993. Immunological response to cellfree antigens of Paracoccidioides brasiliensis: relationship with clinical forms of paracoccidioidomycosis. J Clin Microbiol 31: 671-676.

Camargo ZP, Taborda CP, Rodrigues EG, Travassos LR 1991. The use of cell-free antigens of Paracoccidioides brasiliensis in serological tests. J Med Vet Mycol 29: 31-38.

Carrero LL, Niño-Vega G, Teixeira MM, Carvalho MJA, Soares CMA, Pereira M, Jesuino RSA, McEwen J, Mendoza L, Taylor JW, Felipe MS, San-Blas G 2008. New Paracoccidioides brasiliensis isolate reveals unexpected genomic variability in this human pathogen. Fungal Genet Biol 45: 605-612.
Carvalho KC, Vallejo MC, Camargo ZP, Puccia R 2008. Use of recombinant gp43 isoforms expressed in Pichia pastoris for diagnosis of paracoccidioidomycosis. Clin Vaccine Immunol 15: 622-629.

Corredor GG, Castaño JH, Peralta LA, Díez S, Arango M, McEwen J, Restrepo A 1999. Isolation of Paracoccidioides brasiliensis from the nine-banded armadillo Dasypus novemcinctus in an endemic area for paracoccidioidomycosis in Colombia. Rev Iberoam Micol 16: 216-220.

Elias-Costa MR, Lacaz CS, Kawasaki M, Camargo ZP 2000. Convencional versus molecular diagnostic tests. Med Mycol 38: 139-145.

Farias MR, Werner J, Muro MD, Marques SA, Marques MEA, Franco MF, Ribeiro MG, Custódio CC, Condas LAZ, Bosco SMG, Bagagli E 2005. Canine paracoccidioidomycosis: case report of generalized lymphadenitis. Rev Inst Med Trop Sao Paulo 47: 64.

Ferreira-da-Cruz MF, Francesconi-do-Vale AC, Espinera MC, Wanke B, Galvão-Castro BO 1990. Study of antibodies in paracoccidioidomycosis: follow-up of patients during and after treatment. J Med Vet Mycol 28: 151-157.

Ferri RG 1961. Estudo imunoquímico de antígenos intracelulares. Hospital 58: 917-924.

Franco M, Bagagli E, Cunha M, Chamma LG, Fecchio D 1996. Paracoccidioides brasiliensis antigen batches from the same isolate show immunological and biochemical differences. Mycopathologia 135: 13-19.

Franco M, Lacaz CS, Restrepo-Moreno A, Del Negro G 1994. Paracoccidioidomycosis, CRC Press, Boca Ratón, 410 pp.

Franco M, Peraçoli MT, Soares A, Montenegro R, Mendes RP, Meira DA 1993. Host-parasite relationship in paracoccidioidomycosis. In M Borgers, F Hay, MG Rinaldi, (eds.), Current topics in medical mycology, 5th ed., JR Prous, Barcelona, p. 115-149.

Gesztesi JL, Puccia R, Travassos LR, Vicentini AP, Moraes JZ, Franco MF, Lopes JD 1996. Monoclonal antibodies against the 43,000Da glycoprotein from Paracoccidioides brasiliensis modulate laminin-mediated fungal adhesion to epithelial cells and pathogenesis. Hybridoma 15: 415-422.

Gonzales M, Dugan J, Shafer R 2002. Synonymous-non-synonymous mutation rates between sequences containing ambiguous nucleotides (Syn-SCAN). Bioinformatics 18: 886-887.

Lacaz CS 1994. Paracoccidioides brasiliensis: morphology, evolutionary cycle, maintenance during saprophytic life, biology, virulence, taxonomy. In F Franco, CS Lacaz, A Restrepo-Moreno, G Del Negro (eds.), Paracoccidioidomycosis, CRC Press, Boca Ratón, p. 13-25.

Laemmli UK 1970. Cleavage of structural proteins during the assembly of the head of bacteriophage T4. Nature 227: 680-685.

Matute DR, McEwen JG, Montes BA, San-Blas G, Bagagli E, Rauscher JT, Restrepo A, Morais F, Nino-Vega G, Taylor JW 2006. Cryptic speciation and recombination in the fungus Paracoccidioides brasiliensis as revealed by gene genealogies. Mol Biol Evol 23: 65-73.

Matute DR, Quesada-Ocampo LM, Rauscher JT, McEwen JG 2008. Evidence for positive selection in putative virulence factors within the Paracoccidioides brasiliensis species complex. PLoS Negl Trop Dis 2: e296.

McEwen JG, Bedoya V, Patino MM, Salazar ME, Restrepo A 1987. Experimental murine paracoccidioidomycosis induced by the inhalation of conidia. J Med Vet Mycol 25: 165-175.

Mendes RP 1994. The gamut of clinical manifestations. In F Franco, CS Lacaz, A Restrepo-Moreno, G Del Negro (eds.), Paracoccidioidomycosis, CRC Press, Boca Ratón, p. 233-258. 
Mendes RP, Negroni R, Arechavala A 1994. Treatment and control of cure. In M Franco, CS Lacaz, A Restrepo-Moreno, G Del Negro (eds.), Paracoccidioidomycosis. CRC Press, Boca Ratón, p. 373-392.

Mendes-Giannini MJS, Andreotti PF, Vincenzi LR, da Silva JL, Lenzi HL, Benard G, Zancope-Oliveira R, Guedes HLM, Soares CP 2006. Binding of extracellular matrix proteins to Paracoccidioides brasiliensis. Microbes Infect 8: 1550-1559.

Mendes-Giannini MJS, Bueno JP, Shikanai-Yasuda MA, Stolf AM, Masuda A, Amato Neto V, Ferreira AW 1990. Antibody response to $43 \mathrm{KDa}$ glycoprotein of Paracoccidioides brasiliensis as a marker for the evaluation of patients under treatment. Am J Trop Med Hyg 43: 200-206.

Moreto TC, Marques MEA, Oliveira MLSC, Moris DV, Carvalho LR, Mendes RP 2011. Accuracy of routine diagnostic used in paracoccidioidomycosis patients attended at a university hospital. Trans R Soc Trop Med Hyg 105: 473-478.

Moura-Campos MCR, Gesztesi JL, Vicentini AP, Lopes JD, Camargo ZP 1995. Expression and isoforms of gp43 in different strains of Paracoccidioides brasiliensis. J Med Vet Mycol 33: 223-227.

Naiff RD, Ferreira LCP, Barrete TV, Naiff MF, Arias JR 1986. Paracoccidioidomicose enzoótica em tatus (Dasypus novemcinctus) no estado do Pará. Rev Inst Med Trop Sao Paulo 28: 19-27.

Nei M, Gojobori T 1986. Simple methods for estimating the numbers of synonymous and nonsynonymous nucleotide substitutions. Mol Biol Evol 3: 418-426.

Nei M, Kumar S 2000. Molecular evolution and phylogenetics, Oxford University Press, New York, 348 pp.

Puccia R, Schenkman S, Gorin PAJ, Travassos LR 1986. Exocellular components of Paracoccidioides brasiliensis. Identification of a specific antigen. Infect Immun 53: 199-206.
Ricci G, Mota FT, Wakamatsu A, Serafim RC, Borra RC, Franco M 2004. Canine paracoccidioidomycosis. Med Mycol 42: 379-383.

Salgado-Salazar C, Jones LR, Restrepo A, McEwen J 2010. The human fungal pathogen Paracoccidioides brasiliensis (Onygenales: Ajellomycetaceae) is a complex of two species: phylogenetic evidence from five mitochondrial markers. Cladistics 26: 1-12.

Shikanai-Yasuda MA, Telles Filho FQ, Mendes RP, Colombo AL, Moretti ML, Grupo de consultores do consenso em paracoccidioidomicose 2006. Consenso em paracoccidioidomicose. Rev Soc Bras Med Trop 39: 297-310.

Takayama A, Itano EN, Sano A, Ono MA, Kamei K 2010. An atypical Paracoccidioides brasiliensis clinical isolate based on multiple gene analysis. Med Mycol 48: 64-72.

Teixeira MM, Theodoro RC, Carvalho MJA, Fernandes L, Paes HC, Hahn RC, Mendoza L, Bagagli E, San-Blas G, Felipe MS 2009. Phylogenetic analysis reveals a high level of speciation in the Paracoccidioides genus. Mol Phylogenet Evol 52: 273-283.

Theodoro RC, Bagagli E, Oliveira C 2008. Phylogenetic analysis of PRP8 intein in Paracoccidioides brasiliensis species complex. Fungal Genet Biol 45: 1284-1291.

Trejo-Cháves A, Ramírez-Romero R, Ancer-Rodríguez J, NevárezGarza AM, Rodríguez-Tovar LE 2011. Disseminated paracoccidioidomycosis in a southern two-toed sloth (Choloepus didactylus). J Comp Pathol 144: 231-234.

Vicentini AP 2008. Paracoccidioidomicose: histórico, etiologia, epidemiologia, patogênese, formas clínicas, diagnóstico laboratorial e antígenos. BEPA 5: 11-24.

Vicentini AP, Gesztesi JL, Franco MF, de Souza W, de Moraes JZ, Travassos LR, Lopes JD 1994. Binding of Paracoccidioides brasiliensis to laminin through surface glycoprotein gp43 leads to enhancement of fungal pathogenesis. Infect Immun 62: 1465-1469. 
Mutation pattern observed at $\mathrm{PbGP} 43$ exon 2 region in haplotypes of the Paracoccidioides lutzii group

\begin{tabular}{|c|c|c|c|c|c|c|c|c|c|c|}
\hline Seq 1 & Seq 2 & $\mathrm{sd}$ & nd & $\mathrm{s}$ & $\mathrm{n}$ & ps & pn & ds & $\mathrm{dn}$ & $\mathrm{ds} / \mathrm{dn}$ \\
\hline 01 & 7455 & 0.00 & 2.00 & 96.50 & 326.50 & 0.00 & 0.01 & -0.00 & 0.01 & $*$ \\
\hline 01 & 84 & 0.00 & 1.00 & 96.67 & 326.33 & 0.00 & 0.00 & -0.00 & 0.00 & $*$ \\
\hline 01 & 6810 & 0.00 & 3.00 & 96.50 & 326.50 & 0.00 & 0.01 & -0.00 & 0.01 & $*$ \\
\hline 01 & 717 & 0.00 & 2.00 & 96.50 & 326.50 & 0.00 & 0.01 & -0.00 & 0.01 & $*$ \\
\hline 01 & 3171 & 0.00 & 2.00 & 96.50 & 326.50 & 0.00 & 0.01 & -0.00 & 0.01 & $*$ \\
\hline 01 & 189 & 1.00 & 1.00 & 96.17 & 326.83 & 0.01 & 0.00 & 0.01 & 0.00 & 3.42 \\
\hline 01 & 218 & 0.00 & 2.00 & 96.67 & 326.33 & 0.00 & 0.01 & -0.00 & 0.01 & $*$ \\
\hline 01 & 133 & 12.75 & 37.25 & 96.67 & 326.33 & 0.13 & 0.11 & 0.15 & 0.12 & 1.17 \\
\hline 01 & 769 & 9.62 & 39.38 & 97.17 & 325.83 & 0.10 & 0.12 & 0.11 & 0.13 & 0.81 \\
\hline 7455 & 84 & 0.00 & 1.00 & 96.83 & 326.17 & 0.00 & 0.00 & -0.00 & 0.00 & $*$ \\
\hline 7455 & 6810 & 0.00 & 1.00 & 96.67 & 326.33 & 0.00 & 0.00 & -0.00 & 0.00 & $*$ \\
\hline 7455 & 717 & 0.00 & 0.00 & 96.67 & 326.33 & 0.00 & 0.00 & -0.00 & -0.00 & $*$ \\
\hline 7455 & 3171 & 0.00 & 2.00 & 96.67 & 326.33 & 0.00 & 0.01 & -0.00 & 0.01 & $*$ \\
\hline 7455 & 189 & 1.00 & 3.00 & 96.33 & 326.67 & 0.01 & 0.01 & 0.01 & 0.01 & 1.13 \\
\hline 7455 & 218 & 0.00 & 2.00 & 96.83 & 326.17 & 0.00 & 0.01 & -0.00 & 0.01 & $*$ \\
\hline 7455 & 133 & 12.75 & 37.25 & 96.83 & 326.17 & 0.13 & 0.11 & 0.14 & 0.12 & 1.17 \\
\hline 7455 & 769 & 9.62 & 39.38 & 97.33 & 325.67 & 0.10 & 0.12 & 0.11 & 0.13 & 0.80 \\
\hline 84 & 6810 & 0.00 & 2.00 & 96.83 & 326.17 & 0.00 & 0.01 & -0.00 & 0.01 & $*$ \\
\hline 84 & 717 & 0.00 & 1.00 & 96.83 & 326.17 & 0.00 & 0.00 & -0.00 & 0.00 & $*$ \\
\hline 84 & 3171 & 0.00 & 1.00 & 96.83 & 326.17 & 0.00 & 0.00 & -0.00 & 0.00 & $*$ \\
\hline 84 & 189 & 1.00 & 2.00 & 96.50 & 326.50 & 0.01 & 0.01 & 0.01 & 0.01 & 1.70 \\
\hline 84 & 218 & 0.00 & 1.00 & 97.00 & 326.00 & 0.00 & 0.00 & -0.00 & 0.00 & $*$ \\
\hline 84 & 133 & 12.75 & 36.25 & 97.00 & 326.00 & 0.13 & 0.11 & 0.14 & 0.12 & 1.20 \\
\hline 84 & 769 & 9.62 & 38.38 & 97.50 & 325.50 & 0.10 & 0.12 & 0.11 & 0.13 & 0.83 \\
\hline 6810 & 717 & 0.00 & 1.00 & 96.67 & 326.33 & 0.00 & 0.00 & -0.00 & 0.00 & $*$ \\
\hline 6810 & 3171 & 0.00 & 3.00 & 96.67 & 326.33 & 0.00 & 0.01 & -0.00 & 0.01 & $*$ \\
\hline 6810 & 189 & 1.00 & 4.00 & 96.33 & 326.67 & 0.01 & 0.01 & 0.01 & 0.01 & 0.85 \\
\hline 6810 & 218 & 0.00 & 3.00 & 96.83 & 326.17 & 0.00 & 0.01 & -0.00 & 0.01 & $*$ \\
\hline 6810 & 133 & 12.75 & 38.25 & 96.83 & 326.17 & 0.13 & 0.12 & 0.14 & 0.13 & 1.14 \\
\hline 6810 & 769 & 9.62 & 40.38 & 97.33 & 325.67 & 0.10 & 0.12 & 0.11 & 0.14 & 0.78 \\
\hline 717 & 3171 & 0.00 & 2.00 & 96.67 & 326.33 & 0.00 & 0.01 & -0.00 & 0.01 & $*$ \\
\hline 717 & 189 & 1.00 & 3.00 & 96.33 & 326.67 & 0.01 & 0.01 & 0.01 & 0.01 & 1.13 \\
\hline 717 & 218 & 0.00 & 2.00 & 96.83 & 326.17 & 0.00 & 0.01 & -0.00 & 0.01 & $*$ \\
\hline 717 & 133 & 12.75 & 37.25 & 96.83 & 326.17 & 0.13 & 0.11 & 0.14 & 0.12 & 1.17 \\
\hline 717 & 769 & 9.62 & 39.38 & 97.33 & 325.67 & 0.10 & 0.12 & 0.11 & 0.13 & 0.80 \\
\hline 3171 & 189 & 1.00 & 3.00 & 96.33 & 326.67 & 0.01 & 0.01 & 0.01 & 0.01 & 1.13 \\
\hline 3171 & 218 & 0.00 & 2.00 & 96.83 & 326.17 & 0.00 & 0.01 & -0.00 & 0.01 & $*$ \\
\hline 3171 & 133 & 12.75 & 37.25 & 96.83 & 326.17 & 0.13 & 0.11 & 0.14 & 0.12 & 1.17 \\
\hline 3171 & 769 & 9.62 & 39.38 & 97.33 & 325.67 & 0.10 & 0.12 & 0.11 & 0.13 & 0.80 \\
\hline 189 & 218 & 1.00 & 3.00 & 96.50 & 326.50 & 0.01 & 0.01 & 0.01 & 0.01 & 1.13 \\
\hline 189 & 133 & 11.75 & 37.25 & 96.50 & 326.50 & 0.12 & 0.11 & 0.13 & 0.12 & 1.07 \\
\hline 189 & 769 & 10.62 & 39.38 & 97.00 & 326.00 & 0.11 & 0.12 & 0.12 & 0.13 & 0.90 \\
\hline 218 & 133 & 12.75 & 37.25 & 97.00 & 326.00 & 0.13 & 0.11 & 0.14 & 0.12 & 1.17 \\
\hline 218 & 769 & 9.38 & 39.62 & 97.50 & 325.50 & 0.10 & 0.12 & 0.10 & 0.13 & 0.77 \\
\hline 133 & 769 & 3.00 & 11.00 & 97.50 & 325.50 & 0.03 & 0.03 & 0.03 & 0.03 & 0.91 \\
\hline Mean & 4.19 & 15.09 & 96.80 & 326.20 & 0.04 & 0.05 & 0.05 & 0.05 & 1.13 & \\
\hline
\end{tabular}

$\mathrm{dn}$ : Jukes-Cantor correction for multiple values of proportion of observed nonsynonymous mutations (pn); ds: Jukes-Cantor correction for multiple values of proportion of observed synonymous mutations (ps); ds/dn: rate of synonymous mutations over nonsynonymous mutations; n: number of potential nonsynonymous substitutions; nd: number of observed nonsynonymous mutations; s: number of potential synonymous substitutions; sd: number of observed synonymous mutations. Asterisk means that ds is not significant due to the high similarity among sequences. 
Mutation pattern observed at $\mathrm{PbGP43}$ exon 2 region in haplotypes of the Paracoccidioides brasiliensis group

\begin{tabular}{|c|c|c|c|c|c|c|c|c|c|c|}
\hline Seq 1 & Seq 2 & $\mathrm{sd}$ & nd & $\mathrm{s}$ & $\mathrm{n}$ & ps & $\mathrm{pn}$ & $\mathrm{ds}$ & $\mathrm{dn}$ & $\mathrm{ds} / \mathrm{dn}$ \\
\hline A4 & V3 & 1.00 & 5.00 & 97.83 & 325.17 & 0.01 & 0.02 & 0.01 & 0.02 & 0.66 \\
\hline A4 & V2 & 2.00 & 11.00 & 97.83 & 325.17 & 0.02 & 0.03 & 0.02 & 0.03 & 0.60 \\
\hline A4 & V1 & 2.00 & 5.00 & 97.83 & 325.17 & 0.02 & 0.02 & 0.02 & 0.02 & 1.33 \\
\hline A4 & $\mathrm{C} 1$ & 0.00 & 4.00 & 97.83 & 325.17 & 0.00 & 0.01 & -0.00 & 0.01 & $*$ \\
\hline A4 & B26 & 1.00 & 10.00 & 97.83 & 325.17 & 0.01 & 0.03 & 0.01 & 0.03 & 0.33 \\
\hline A4 & B25 & 0.00 & 1.00 & 98.00 & 325.00 & 0.00 & 0.00 & -0.00 & 0.00 & $*$ \\
\hline A4 & B23 & 2.00 & 11.00 & 97.50 & 325.50 & 0.02 & 0.03 & 0.02 & 0.03 & 0.60 \\
\hline A4 & B21 & 0.00 & 3.00 & 97.83 & 325.17 & 0.00 & 0.01 & -0.00 & 0.01 & $*$ \\
\hline A4 & B18 & 0.00 & 5.00 & 97.83 & 325.17 & 0.00 & 0.02 & -0.00 & 0.02 & $*$ \\
\hline A4 & B1 & 1.00 & 1.00 & 98.00 & 325.00 & 0.01 & 0.00 & 0.01 & 0.00 & 3.33 \\
\hline V3 & V2 & 3.00 & 8.00 & 97.33 & 325.67 & 0.03 & 0.02 & 0.03 & 0.02 & 1.26 \\
\hline V3 & V1 & 1.00 & 0.00 & 97.33 & 325.67 & 0.01 & 0.00 & 0.01 & -0.00 & $*$ \\
\hline V3 & $\mathrm{C} 1$ & 1.00 & 1.00 & 97.33 & 325.67 & 0.01 & 0.00 & 0.01 & 0.00 & 3.36 \\
\hline V3 & B26 & 2.00 & 7.00 & 97.33 & 325.67 & 0.02 & 0.02 & 0.02 & 0.02 & 0.96 \\
\hline V3 & B25 & 1.00 & 4.00 & 97.50 & 325.50 & 0.01 & 0.01 & 0.01 & 0.01 & 0.83 \\
\hline V3 & B23 & 3.00 & 8.00 & 97.00 & 326.00 & 0.03 & 0.02 & 0.03 & 0.02 & 1.27 \\
\hline V3 & B21 & 1.00 & 2.00 & 97.33 & 325.67 & 0.01 & 0.01 & 0.01 & 0.01 & 1.68 \\
\hline V3 & B18 & 1.00 & 2.00 & 97.33 & 325.67 & 0.01 & 0.01 & 0.01 & 0.01 & 1.68 \\
\hline V3 & $\mathrm{B} 1$ & 2.00 & 4.00 & 97.50 & 325.50 & 0.02 & 0.01 & 0.02 & 0.01 & 1.68 \\
\hline V2 & V1 & 4.00 & 8.00 & 97.33 & 325.67 & 0.04 & 0.02 & 0.04 & 0.02 & 1.69 \\
\hline V2 & $\mathrm{C} 1$ & 2.00 & 7.00 & 97.33 & 325.67 & 0.02 & 0.02 & 0.02 & 0.02 & 0.96 \\
\hline $\mathrm{V} 2$ & B26 & 1.00 & 1.00 & 97.33 & 325.67 & 0.01 & 0.00 & 0.01 & 0.00 & 3.36 \\
\hline V2 & B25 & 2.00 & 10.00 & 97.50 & 325.50 & 0.02 & 0.03 & 0.02 & 0.03 & 0.66 \\
\hline $\mathrm{V} 2$ & B23 & 0.00 & 1.00 & 97.00 & 326.00 & 0.00 & 0.00 & -0.00 & 0.00 & $*$ \\
\hline V2 & B21 & 2.00 & 8.00 & 97.33 & 325.67 & 0.02 & 0.02 & 0.02 & 0.02 & 0.83 \\
\hline V2 & B18 & 2.00 & 8.00 & 97.33 & 325.67 & 0.02 & 0.02 & 0.02 & 0.02 & 0.83 \\
\hline $\mathrm{V} 2$ & $\mathrm{~B} 1$ & 3.00 & 10.00 & 97.50 & 325.50 & 0.03 & 0.03 & 0.03 & 0.03 & 1.00 \\
\hline V1 & $\mathrm{C} 1$ & 2.00 & 1.00 & 97.33 & 325.67 & 0.02 & 0.00 & 0.02 & 0.00 & 6.77 \\
\hline V1 & B26 & 3.00 & 7.00 & 97.33 & 325.67 & 0.03 & 0.02 & 0.03 & 0.02 & 1.44 \\
\hline V1 & B25 & 2.00 & 4.00 & 97.50 & 325.50 & 0.02 & 0.01 & 0.02 & 0.01 & 1.68 \\
\hline V1 & B23 & 4.00 & 8.00 & 97.00 & 326.00 & 0.04 & 0.02 & 0.04 & 0.02 & 1.70 \\
\hline V1 & B21 & 2.00 & 2.00 & 97.33 & 325.67 & 0.02 & 0.01 & 0.02 & 0.01 & 3.38 \\
\hline V1 & $\mathrm{B} 18$ & 2.00 & 2.00 & 97.33 & 325.67 & 0.02 & 0.01 & 0.02 & 0.01 & 3.38 \\
\hline V1 & $\mathrm{B} 1$ & 3.00 & 4.00 & 97.50 & 325.50 & 0.03 & 0.01 & 0.03 & 0.01 & 2.54 \\
\hline $\mathrm{C} 1$ & B26 & 1.00 & 6.00 & 97.33 & 325.67 & 0.01 & 0.02 & 0.01 & 0.02 & 0.55 \\
\hline $\mathrm{C} 1$ & B25 & 0.00 & 3.00 & 97.50 & 325.50 & 0.00 & 0.01 & -0.00 & 0.01 & $*$ \\
\hline $\mathrm{C} 1$ & B23 & 2.00 & 7.00 & 97.00 & 326.00 & 0.02 & 0.02 & 0.02 & 0.02 & 0.96 \\
\hline $\mathrm{C} 1$ & B21 & 0.00 & 1.00 & 97.33 & 325.67 & 0.00 & 0.00 & -0.00 & 0.00 & $*$ \\
\hline $\mathrm{C} 1$ & B18 & 0.00 & 1.00 & 97.33 & 325.67 & 0.00 & 0.00 & -0.00 & 0.00 & $*$ \\
\hline $\mathrm{C} 1$ & $\mathrm{~B} 1$ & 1.00 & 3.00 & 97.50 & 325.50 & 0.01 & 0.01 & 0.01 & 0.01 & 1.11 \\
\hline B26 & B25 & 1.00 & 9.00 & 97.50 & 325.50 & 0.01 & 0.03 & 0.01 & 0.03 & 0.37 \\
\hline B26 & B23 & 1.00 & 1.00 & 97.00 & 326.00 & 0.01 & 0.00 & 0.01 & 0.00 & 3.38 \\
\hline B26 & B21 & 1.00 & 7.00 & 97.33 & 325.67 & 0.01 & 0.02 & 0.01 & 0.02 & 0.47 \\
\hline B26 & B18 & 1.00 & 7.00 & 97.33 & 325.67 & 0.01 & 0.02 & 0.01 & 0.02 & 0.47 \\
\hline B26 & B1 & 2.00 & 9.00 & 97.50 & 325.50 & 0.02 & 0.03 & 0.02 & 0.03 & 0.74 \\
\hline B25 & B23 & 2.00 & 10.00 & 97.17 & 325.83 & 0.02 & 0.03 & 0.02 & 0.03 & 0.67 \\
\hline B25 & B21 & 0.00 & 2.00 & 97.50 & 325.50 & 0.00 & 0.01 & -0.00 & 0.01 & $*$ \\
\hline B25 & B18 & 0.00 & 4.00 & 97.50 & 325.50 & 0.00 & 0.01 & -0.00 & 0.01 & $*$ \\
\hline B25 & $\mathrm{B} 1$ & 1.00 & 0.00 & 97.67 & 325.33 & 0.01 & 0.00 & 0.01 & -0.00 & $*$ \\
\hline B23 & B21 & 2.00 & 8.00 & 97.00 & 326.00 & 0.02 & 0.02 & 0.02 & 0.02 & 0.84 \\
\hline B23 & B18 & 2.00 & 8.00 & 97.00 & 326.00 & 0.02 & 0.02 & 0.02 & 0.02 & 0.84 \\
\hline B23 & B1 & 3.00 & 10.00 & 97.17 & 325.83 & 0.03 & 0.03 & 0.03 & 0.03 & 1.01 \\
\hline B21 & B18 & 0.00 & 2.00 & 97.33 & 325.67 & 0.00 & 0.01 & -0.00 & 0.01 & $*$ \\
\hline B21 & $\mathrm{B} 1$ & 1.00 & 2.00 & 97.50 & 325.50 & 0.01 & 0.01 & 0.01 & 0.01 & 1.67 \\
\hline B18 & B1 & 1.00 & 4.00 & 97.50 & 325.50 & 0.01 & 0.01 & 0.01 & 0.01 & 0.83 \\
\hline Mean & 1.45 & 5.04 & 97.42 & 325.58 & 0.01 & 0.02 & 0.02 & 0.02 & 1.52 & \\
\hline
\end{tabular}

$\mathrm{dn}$ : Jukes-Cantor correction for multiple values of proportion of observed nonsynonymous mutations (pn); ds: Jukes-Cantor correction for multiple values of proportion of observed synonymous mutations (ps); ds/dn: rate of synonymous mutations over nonsynonymous mutations; n: number of potential nonsynonymous substitutions; nd: number of observed nonsynonymous mutations; s: number of potential synonymous substitutions; sd: number of observed synonymous mutations. Asterisk means that ds is not significant due to the high similarity among sequences. 